\title{
Снижение частоты гепато-билиарных осложнений у больных муковисцидозом в результате противовоспалительной терапии
}

1 - Научно-клинический отдел муковисцидоза ГУ "Медико-генетический научный центр РАМН": 115478, Москва, ул. Москворечье, 1

2 - Российская детская клиническая больница Росздрава: 117513, Москва, Ленинский пр-т, 117

\section{A.L.Pukhalsky, G.V.Shmarina, N.Yu.Kashirskaya, L.V.Perederko, N.I.Kapranov \\ Anti-inflammatory therapy reduces a rate of hepatobiliary disorders in cystic fibrosis patients}

\begin{abstract}
Summary
Anti-inflammatory therapy is a common but not an obligatory component of cystic fibrosis (CF) lung disease treatment. This study was aimed at investigation of CF clinical course in patients treated with basic therapy or receiving additional anti-inflammatory drugs. This study analyzed hospital medical records of $183 \mathrm{CF}$ patients aged $<19 \mathrm{yrs}$. Of them, 96 were treated with basic therapy and 87 patients received basic therapy and additional anti-inflammatory treatment with azithromycin (AZ; 48 patients) or prednisolone (PD; 39 patients) in the alternating mode $(0.3-0.5 \mathrm{mg} / \mathrm{kg}$ of the body weight every other day). Plasma levels of ACTH and cytokines (TNF- $\alpha$, IFN- $\gamma$, IL-10, TGF- $\beta 1$ ) of CF patients were compared with those of healthy children. The patients treated with PD or AZ had lower rate of hepatobiliary disorders compared with those who did not receive additional ant-inflammatory therapy (WAT). Cirrhosis was diagnosed in 38 of 96 WAT patients and only in 7 of 39 ( $p=0.007)$ and in 4 of 48 $(p=0.01)$ children treated with PD and AZ, respectively. Among 38 WAT patients with cirrhosis, 24 patients had ultrasound signs, 11 had portal hypertension and 3 had biliary cirrhosis. ACTH and blood cytokine levels changed similarly in all the patients excepting IL-10, which was significantly higher in WAT patients as compared with healthy children and CF patients treated with additional anti-inflammatory drugs. In conclusion, the anti-inflammatory therapy could improve the control of inflammation and reduce the rate of hepatobiliary disorders in CF patients.

Key words: cystic fibrosis, anti-inflammatory therapy, cytokines, azithromycin, prednisolone, hepatobiliary disorders.
\end{abstract}

\section{Резюме}

Противовоспалительная терапия является частым, но не обязательным компонентом лечения муковисцидоза. Целью настоящего исследования была сравнительная оценка особенностей течения муковисцидоза у больных, получавших только базисную терапию, и у больных, дополнительно принимавших противовоспалительные препараты. Были проанализированы истории болезни 183 пациентов моложе 19 лет. В лечении 96 больных использовались только базисные препараты, и 87 пациентов, помимо базисной терапии, получали азитромицин (48 больных) или преднизолон (39 больных) в форме альтернирующего курса (0,3-0,5 мг на 1 кг массы тела через день). Уровень адренокортикотропного гормона (АКТГ) и цитокинов (фактор некроза опухоли- $\alpha$, интерлейкин-10 (IL-10), интерферон- $\gamma$, трансформирующий ростовой фактор- $\beta 1$ ) в плазме крови больных сравнивали с аналогичными показателями здоровых детей. Частота гепатобилиарных осложнений у больных, получавших преднизолон или азитромицин, была значимо ниже, чем у детей без противовоспалительной терапии (БПТ). Диагноз цирроза был поставлен 38 из 96 пациентов группы БПТ, тогда как подобные осложнения наблюдались только у 7 из $39(p=0,007)$ и у 4 из $48(p=0,01)$ больных, лечившихся преднизолоном и азитромицином соответственно. Среди 38 больных группы БПТ с диагнозом цирроз у 24 пациентов обнаруживались ультразвуковые изменения, у 11 - портальная гипертензия и у 3 - признаки билиарного цирроза. У всех обследованных выявлялись сходные изменения содержания АКТГ и цитокинов, за исключением уровня IL-10, который был значимо выше у больных группы БПТ, по сравнению со здоровыми детьми.

Ключевые слова: муковисцидоз, противовоспалительная терапия, цитокины, азитромицин, преднизолон, гепато-билиарные осложнения.

Муковисцидоз - одно из наиболее хорошо изученных аутосомно-рецессивных наследственных заболеваний. Первичный генетический дефект связан с мутацией в гене, кодирующем белок клеточной мембраны, который образует канал для ионов хлора. Этот дефект приводит к нарушению электролитного транспорта между клетками и межклеточной жидкостью, в результате чего всасывание натрия и воды клетками эпителия увеличивается в $2-3$ раза. Потеря воды повышает вязкость экскретов, что нарушает функцию бронхолегочной системы, поджелудочной железы, кишечника, урогенитального тракта [1]. Наибольшее влияние на продолжительность жизни больных муковисцидозом оказывают инфекционные осложнения со стороны органов дыхания. Характерной особенностью легочной болезни при му- ковисцидозе является бурная воспалительная реакция, сопровождающаяся повышенной продукцией провоспалительных цитокинов и выраженной нейтрофильной инфильтрацией [2]. В связи с этим противовоспалительная терапия при муковисцидозе применяется все чаще, хотя она до сих пор не включена в обязательный протокол ведения таких больных ни в нашей стране, ни за рубежом [3, 4]. Обычно используются антибиотики из группы макролидов (азитромицин или кларитромицин), нестероидные противовоспалительные препараты (ибупрофен или нимесулид) и реже альтернирующий курс системных глюкокортикостероидов (ГКС) в низких дозах. Согласно выводу, сделанному на основании 6 опубликованных рандомизированных контролируемых исследований, ингаляционные ГКС 
не могут рассматриваться в качестве средств для противовоспалительной терапии [5, 6]. Существует обширная литература, подтверждающая высокую эффективность назначения макролидов при гнойных заболеваниях легких, включая диффузный панбронхиолит и муковисцидоз. Для обоих состояний характерны вторичное инфицирование Pseudomonas aeruginosa и нейтрофильная инфильтрация слизистой оболочки дыхательных путей. В результате лечения макролидными антибиотиками наблюдали улучшение показателей функции внешнего дыхания (ФВД), включая форсированную жизненную емкость легких (ФЖЕЛ) и объем форсированного выдоха за 1-ю с $\left(\mathrm{OФB}_{1}\right)[7,8]$.

Сложилось мнение, что пероральное применение ГКС при легочной форме муковисцидоза эффективно, но длительное их использование сопряжено с выраженными побочными явлениями. В то же время частота осложнений от лечения ГКС напрямую зависит от применяемой дозы и продолжительности лечения. У больных, получающих преднизолон в течение длительного периода, возможны эндокринные, офтальмологические, психоневрологические и гастроинтестинальные нарушения, а также осложнения со стороны сердечнососудистой, мочевыводящей и костно-мышечной систем. При этом у пациентов, получавших преднизолон в форме альтернирующего курса, подобные нежелательные явления отсутствовали, несмотря на тщательно проводившееся обследование.

При длительном применении ГКС существует опасность того, что больной не сможет прекратить прием препарата без риска существенного ухудшения своего состояния. Системный прием ГКС в виде альтернирующего курса лишен этого недостатка. Так, у 10 из 20 пациентов в возрасте моложе 5 лет, которым был назначен альтернирующий курс преднизолона, в разное время прием данного средства был отменен без последующего ухудшения функции легких [9].

\section{Материалы и методы}

\section{Пациенты}

Были проанализированы истории болезни и амбулаторные карты 183 больных муковисцидозом моложе 19 лет, наблюдавшихся в НКО муковисцидоза МГНЦ РАМН (Москва) и в Российской детской клинической больнице (Москва) с февраля 1991 г. по декабрь 2006 г. Диагноз муковисцидоз ставился на основании повышенного содержания хлоридов пота (> 60 мМ/л), характерной клинической картины и / или в результате определения мутации в обоих аллелях CFTR. Характеристики больных представлены в табл. 1. Из 165 генотипированных пациентов 55 оказались гомозиготами по гену $\Delta \mathrm{F} 508$ и 73 больных гетерозиготами. У 37 пациентов были обнаружены другие мутации, и в 37 случаях не удалось обнаружить ни одну из известных мутаций. У 98 больных имела место хроническая колонизация мукоидной формой P. aeruginosa. Все пациенты получали базисную терапию (муколитики, мультивитамины, высококалорийная диета и микросферические энзимы). В случае острого осложнения применяли антибактериальную терапию, состав которой зависел от результатов микробиологического исследования мокроты. Больным, инфицированным P. aeruginosa, назначали цефалоспорины 3-го поколения в комбинации с аминогликозидами или ципрофлоксацином. 96 пациентов получали только базисную терапию, и 87 больных, одновременно с базисным лечением, получали азитромицин (48 человек) или преднизолон (39 человек). Азитромицин назначали в соответствии с протоколом для больных Московского региона: пациентам с массой тела $\geq 40$ кг в дозе 500 мг, пациентам с массой тела $<40$ кг - в дозе 250 мг. Препарат применяли по схеме "понедельник-среда-пятница" (1 таблетка на прием). Преднизолон назначали при развитии выраженной обструкции дыхательных путей и / или ателектаза в дозе 1 мг на 1 кг массы тела в день. период лечения

Таблица 1

Характеристика больных

\begin{tabular}{|c|c|c|c|c|}
\hline & $\begin{array}{c}\text { БПТ } \\
(n=96)\end{array}$ & $\begin{array}{c}\text { Преднизолон } \\
(n=39)\end{array}$ & $\begin{array}{l}\text { Азитромицин } \\
(n=48)\end{array}$ & $\begin{array}{c}\text { Преднизолон + азитромицин } \\
(n=87)\end{array}$ \\
\hline Возраст, лет & $12,5 \pm 0,5$ & $12,5 \pm 0,6$ & $14,0 \pm 0,4^{*}$ & $13,3 \pm 0,4$ \\
\hline Пол (м / ж) & $56 / 40$ & $16 / 23$ & $25 / 23$ & 41 / 46 \\
\hline Тяжесть, \% & 73,9 & $92,3^{* *}$ & 79,2 & 85,1 \\
\hline P. aeruginosa, \% & 49,5 & $82,1^{* *}$ & $83,3^{* *}$ & $82,8^{* *}$ \\
\hline$\Delta \mathrm{F} 508, \%$ & 77,0 & 73,7 & 82,5 & 78,2 \\
\hline ФЖЕЛ, \% & $80,4 \pm 2,5$ & $69,1 \pm 4,3^{*}$ & $82,5 \pm 3,4$ & $76,6 \pm 2,8$ \\
\hline $\mathbf{O} \Phi \mathbf{B}_{1}, \%$ & $74,1 \pm 2,9$ & $59,4 \pm 4,8^{*}$ & $74,4 \pm 3,8$ & $67,8 \pm 3,1$ \\
\hline Гепатит, $n$ (\%) & $5(5,2)$ & $3(7,7)$ & $2(4,1)$ & $5(5,7)$ \\
\hline Цирроз, $n(\%)$ & $38(39,6)$ & $7(17,9)^{* *}$ & $4(8,3)^{* *}$ & $11(12,6)^{\star *}$ \\
\hline Ультразвуковые признаки цирроза, $n$ (\%) & $24(25)$ & $5(12,8)$ & $2(4,1)^{* *}$ & $7(8,0)^{* *}$ \\
\hline Синдром портальной гипертензии, $n$ (\%) & $11(11,5)$ & $1(2,6)$ & $0^{* *}$ & $1(1,1)^{* *}$ \\
\hline Билиарный цирроз, n (\%) & $3(3,1)$ & $1(2,6)$ & $2(4,1)$ & $3(3,4)$ \\
\hline $\begin{array}{l}\text { Возраст, в котором проявилось } \\
\text { заболевание, лет }\end{array}$ & $11,6 \pm 0,7$ & $13,4 \pm 1,0$ & $11,0 \pm 1,4$ & $12,5 \pm 0,9$ \\
\hline
\end{tabular}

Примечание: * - p<0,05 по сравнению с группой БПТ (t-критерий Стьюдента); ** - $p<0,05$ по сравнению с группой БПТ (критерий $\left.\chi^{2}\right)$. 
составил 2-3 нед. вплоть до стойкого улучшения состояния больного. Затем дозу постепенно снижали, и терапию продолжали в форме альтернирующего курса (0,1-0,5 мг на 1 кг массы тела через день) на протяжении нескольких лет.

\section{Определение уровня цитокинов и адренокортикотропного гормона}

Кровь собирали из локтевой вены в пробирки с этилендиаминтетрауксусной кислотой. Пробирки центрифугировали при $400 \mathrm{~g}$ в течение 10 мин при $+4{ }^{\circ} \mathrm{C}$, собирали плазму, разливали по аликвотам и хранили при температуре $-60{ }^{\circ} \mathrm{C}$. В образцах плазмы определяли содержание фактора некроза опухоли- $\alpha$ (TNF- $\alpha$ ), интерлейкина-10 (IL-10), интерферона- $\gamma$ (INF- $\gamma$ ), трансформирующего ростового фактора- $\beta 1$ (TGF- $\beta 1$ ) и адренокортикотропного гормона (АКТГ) с помощью коммерческих иммуноферментных наборов.

\section{Статистический анализ}

Различия между группами оценивали с помощью t-критерия Стьюдента и критерия $\chi^{2}$ с поправкой Йейтса.

\section{Результаты}

Результаты, представленные в табл. 1, демонстрируют, что течение легочного процесса в группе больных муковисцидозом, получавших преднизолон, было существенно более тяжелым, чем у больных, лечившихся азитромицином, или у пациентов без противовоспалительной терапии (БПТ). Так, непосредственно перед назначением преднизолона уровень ФЖЕЛ и ОФВ у 12 из 27 пациентов был < $40 \%$ от ожидаемых величин. У большинства больных, получавших противовоспалительную терапию, имела место колонизация $P$. aeruginosa; в группе БПТ она обнаруживалась менее чем у $1 / 2$ пациентов. Как показано на рис. 1, оба использованных метода противовоспалительной терапии оказались достаточно эффективными. Так, после назначения азитромици-

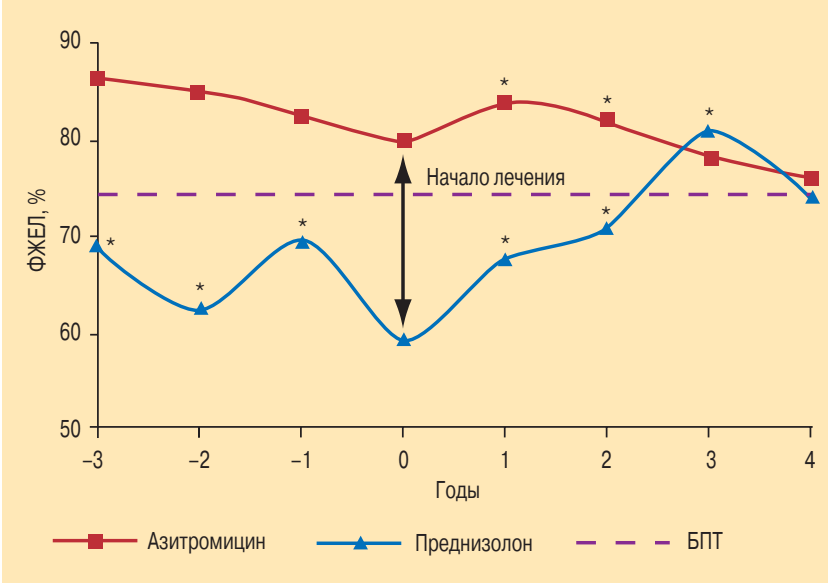

Рис. 1. Динамика показателя ФЖЕЛ у больных муковисцидозом, получавших азитромицин или АКП. Данные представлены в виде средних величин

Примечание: * $-p<0,05$ по сравнению с точкой "начало лечения"; БПТ группа больных, не получавших противовоспалительной терапии. на скорость снижения показателей ФЖЕЛ заметно снижалась. У больных, получавших альтернирующий курс преднизолона, регистрировалось значимое повышение ФЖЕЛ, несмотря на первоначально низкие значения показателей ФВД, и через 3 года после начала лечения данным препаратом значения ФЖЕЛ у большинства пациентов не отличались от показателей больных, получавших только базисную терапию.

Ретроспективный анализ продемонтрировал, что у больных, лечившихся преднизолоном или азитромицином, частота гепато-билиарных осложнений была ниже, чем в группе БПТ. Диагноз цирроз был поставлен 38 из 96 пациентов БПТ, тогда как подобное осложнение отмечалось только у 7 из $39(p=0,01)$ и у 4 из 48 ( $p=0,007)$ больных, получавших соответственно преднизолон и азитромицин. Из 38 пациентов группы БПТ с диагнозом цирроз у 24 обнаруживались ультразвуковые изменения печени, у 11 портальная гипертензия и у 3 - билиарный цирроз. Частота последнего у больных с противовоспалительной терапией и без нее была одинаковой (соответственно 1 и 2 случая в группах преднизолона и азитромицина). В то же время частота выявления ультразвуковых признаков цирроза и случаев портальной гипертензии была значимо ниже у больных, получавших противовоспалительную терапию (табл. 1; рис. 2).

Результаты, представленные в табл. 2, были получены при госпитализации пациентов в отделение наследственной патологии Российской детской клинической больницы или при плановом посещении ими НКО муковисцидоза МГНЦ РАМН в 2006-2007 гг. У всех обследованных больных были выявлены заметные нарушения со стороны иммунной системы. Tак, уровень INF- $\gamma$ у пациентов всех обследованных групп был значимо выше показателей, характерных для здоровых детей. Хотя подобное повышение содержания INF- $\gamma$ в периферической крови больных муковисцидозом наблюдалось и ранее [8], до сих пор мы не имеем удовлетворительного объяснения

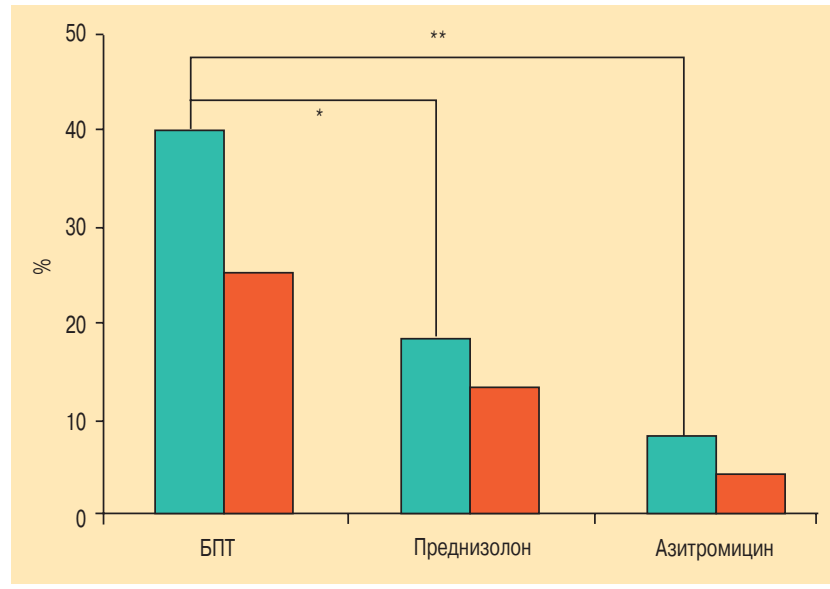

Рис. 2. Частота гепато-билиарных осложнений у пациентов, получавших противовоспалительную терапию

Примечание: зеленые столбцы - общее количество пациентов с циррозом печени; красные столбцы - количество пациентов с ультразвуковыми признаками цирроза печени; ${ }^{*}-p=0,01 ; * *-p<0,05$. 
причин такого повышения. У больных группы БПТ уровень цитокинов, обладающих профибротической и иммуносупрессивной активностью, таких как IL-10 и TGF- $\beta 1$, также существенно превышал нормальные показатели. В то же время у пациентов, получавших противовоспалительную терапию, содержание IL-10 в периферической крови было нормальным. Хотя у больных, принимавших азитромицин, уровень TGF- $\beta 1$ оставался высоким, у пациентов, получавших преднизолон в форме альтернирующего курса, величина этого показателя была такой же, как и у здоровых детей.

\section{Обсуждение}

В человеческом организме и организме высших позвоночных действуют 2 главных механизма, контролирующих реакцию воспаления: 1-й осуществляется с помощью ГКС и катехоламинов (главных гормонов стресса), а 2-й - посредством регуляторных Т-клеток (Treg). Treg (ранее известные как Т-супрессоры) представляют собой крайне важную для поддержания гомеостаза клеточную популяцию, ответственную, в частности, за иммунологическую толерантность к собственным антигенам и эффективный контроль иммунных реакций на множество чужеродных антигенов. Кроме того, Treg способны ограничивать реакцию воспаления [10]. Одной из важнейших функций ГКС и катехоламинов является защита организма от продуктов реакции воспаления, обладающих выраженным тканеповреждающим потенциалом (таких как провоспалительные цитокины, протеазы и свободные радикалы) [11]. Кроме того, ГКС индуцируют экспрессию клетками Treg GITR (glucocorticoid-induced tumour necrosis factor receptor - рецептор для фактора некроза опухолей, индуцированный ГК) [12, 13]. В условиях антигенной стимуляции многие клетки, в т. ч. макрофаги, интенсивно продуцируют TNF- $\alpha$, который через GITR стимулирует Treg, заставляя их вступать в пролиферацию. Известно, что пролиферирующие Treg временно теряют свою функциональную активность, которая восстанавливается лишь после выхода клетки из цикла деления [12]. Такая временная потеря супрессорной активности дает возможность иммунной системе временно выйти из-под контроля Treg и быстрее реализовать свой защитный потенциал [14]. Со временем, по мере истощения ростовых факторов, пролиферация Treg прекращается, и клетки восстанавливают свою функциональную активность, что ведет к постепенному затуханию иммунной реакции.

В норме оба механизма контроля за реакцией воспаления, быстрый (ГКС и катехоламины) и медленный (Treg), хорошо сбалансированы, однако у больных муковисцидозом это равновесие может быть нарушено. Хорошо известно, что мутация в гене CFTR ведет к развитию патологических изменений во всех органах, содержащих железы, секретирующие слизь, включая эпителий, выстилающий дыхательные пути, в которых продукция вязкого секрета становится причиной присоединения инфекции. Большинство пациентов с муковисцидозом переживают в течение жизни множество эпизодов обострения легочного заболевания, в результате чего их иммунная система постоянно подвергается атакам со стороны разнообразных патогенов. Чтобы избежать негативных последствий избыточной антигенной нагрузки в виде рекрутирования в зону воспаления нейтрофилов и высокого уровня медиаторов воспаления, организм вынужден постоянно мобилизовывать гормоны стресса. Со временем повторные эпизоды обострения легочной инфекции истощают адаптационный потенциал надпочечников и контроль за воспалением переходит от кортизола и катехоламинов к Treg, которые становятся главным инструментом, с помощью которого организм способен контролировать реакцию воспаления [15]. Этот способ регуляции, более медленный и грубый, не позволяет тонко настраивать иммунную систему, и каждый новый "вызов" со стороны окружающей среды ведет к дальнейшему накоплению Treg, что, в свою очередь, становится причиной стойкой иммуносупрессии. Действительно, у больных группы БПТ регистрировался повышенный уровень IL-10 и TGF- $\beta 1$ одновременно с низким содержанием АКТГ в сыворотке (табл. 1). Вполне возможно, что хроническая инфекция $P$. aeruginosa и Burkholderia cenocepacia является следствием подавления протективного иммунитета, защищающего от этих микроорганизмов, регуляторными Т-клетками. Избыток Treg может также оказывать влияние на дифференцировку предшественников Т-клеток, способствуя образованию Tr1- и / или Тh3-лимфоцитов. Именно эти клетки несут основную ответственность за продукцию TGF- $\beta 1$ и IL-10 [16]. Следствием такого аберрантного

Таблица 2 Содержание АКТГ и уровень цитокинов в периферической крови здоровых детей и больных муковисцидозом

\begin{tabular}{l|c|c|c|c|} 
& Здоровые дети $(n=25)$ & Преднизолон $(n=16)$ & Азитромицин $(n=37)$ & БПт (n=83) \\
\hline TNF- $\alpha$ (общий), нг/мл & $17,1(14,3 \div 22,4)$ & $19,6(0 \div 42,6)$ & $18,6(1,9 \div 620,6)$ & $9,2(0 \div 92,5)$ \\
\hline IL-10 (общий), нг/мл & $7,0(2,9 \div 10,8)$ & $6,0(2,0 \div 27,0)$ & $5,2(2,1 \div 25,8)$ & $8,3^{*}(0,2 \div 215,3)$ \\
INF- $\gamma$, пг/мл & $12,9(0 \div 90,6)$ & $116,9^{*}(0 \div 486,6)$ & $32,5^{*}(0 \div 1063,5)$ & $52,9^{*}(0 \div 2299,7)$ \\
\hline TGF- $\beta 1$, пг/мл & $12,2(0 \div 90,6)$ & $22,0(0 \div 139,2)$ & $73,2^{*}(0 \div 238,1)$ & $41,5^{*}(0 \div 279,6)$ \\
\hline AKTГ, пг/мл & $9,2(4,7 \div 17,9)$ & $4,2(0 \div 34,4)$ & $7,5(1,2 \div 41,0)$ & $4,6(0 \div 138,7)$
\end{tabular}

Примечание: результаты представлены в виде медиан, минимальное значение $\div$ максимальное значение; * - p < 0,05 по сравнению с группой здоровых детей (непарный критерий Вилкоксона). 
течения реакции воспаления может быть, в частности, фиброз внутренних органов, включая фибротические процессы в печени с исходом в цирроз. Альтернирующий курс преднизолона может частично восполнить дефицит гормонов стресса. Такого рода заместительная терапия оказывает не только непосредственное противовоспалительное действие, но и предотвращает избыточное накопление Treg. Полученные нами данные заставляют думать, что в условиях истощения гипоталамо-гипофизарнонадпочечниковой оси, когда главным механизмом, способным ограничить реакцию воспаления, становятся Treg, даже небольшое повышение базисного уровня ГК влияет на содержание Treg. Действительно, у пациентов, получавших преднизолон в форме альтернирующего курса, содержание в крови IL-10 и TGF- $\beta 1$ не отличалось от показателей, наблюдаемых у здоровых детей, что является косвенным свидетельством отсутствия у них избыточной активности Treg (табл. 2). Несмотря на то, что у больных, получавших в качестве противовоспалительной терапии азитромицин, уровень TGF- $\beta 1$ по-прежнему был повышен, содержание IL-10 было значимо ниже, чем у пациентов в группе БПТ. По-видимому, продолжительная терапия азитромицином также способна частично восстанавливать контроль за реакцией воспаления.

\section{Заключение}

Таким образом, полученные данные показывают, что противовоспалительная терапия снижает частоту гепато-билиарных осложнений у больных муковисцидозом, что может быть связано с уменьшением интенсивности процессов фиброза во внутренних органах.

\section{Литература}

1. Капранов Н.И., Каширская Н.Ю., Петрова Н.В. Муковисцидоз: достижения и проблемы на современном этапе. Мед. генетика 2004; 9: 398-401.

2. Chmiel J.F., Berger M., Konstan M.W. The role of inflammation in the pathophysiology of CF lung disease. Clin. Rev. Allergy Immunol. 2002; 23: 5-27.

3. Konstan M.W., Davis P.B. Pharmacological approaches for the discover y and development of new anti-inflammatory agents for the treatment of cystic fibrosis. Adv. Drug Deliv. Rev. 2002; 54: 1409-1423.

4. Koehler D.R., Downey G.P., Sweezey N.B. et al. Lung inflammation as a therapeutic target in cystic fibrosis. Am. J. Respir. Cell Mol. Biol. 2004; 31: 377-381.
5. Balfour-Lynn I., Walters S., Dezateux C. Inhaled corticosteroids for cystic fibrosis. Cochrane Database Syst. Rev. 2001; Art. No: CD001915. DOI: 10.1002/14651858. CD001915.

6. Balfour-Lynn I.M., Lees B., Hall P. et al. Multicenter randomized controlled trial of withdrawal of inhaled corticosteroids in cystic fibrosis. Am. J. Respir. Crit. Care Med. 2006; 173: 1356-1362.

7. Southern K.W., Barker P.M. Azithromycin for cystic fibrosis. Eur. Respir. J. 2004; 24: 834-838.

8. Pukhalsky A.L., Shmarina G.V., Kapranov N.I. et al. Antiinflammatory and immunomodulating effects of clarithromycin in patients with cystic fibrosis lung disease. Mediators Inflamm. 2004; 13: 111-117.

9. Pukhalsky A., Shmarina G., Pukhalskaya D. et al. Can different approaches to anti-inflammatory therapy result in different outcomes in cystic fibrosis patients? (abstr.) Eur. Respir. J. 2007; 30 (suppl. 51): 31S-32S.

10. Sakaguchi S., Ono M., Setoguchi R. et al. Foxp3+CD25+ $\mathrm{CD} 4+$ natural regulatory $\mathrm{T}$ cells in dominant self-tolerance and autoimmune disease. Immunol. Rev. 2006; 212: 8-27.

11. Elenkov I.J., Iezzoni D.G., Daly A. et al. Cytokine disregulation, inflammation and well-being. Neuroimmunomodulation 2005; 12: 255-269.

12. Woiciechowsky C., Schoning B., Lanksch W.R. et al. Mechanisms of brain-mediated systemic anti-inflammatory syndrome causing immunodepression. J. Mol. Med. 1999; 77: 769-780.

13. Apostolou I., Sarukhan A., Klein L., Von Boehmer H. Origin of regulatory T cells with known specificity for antigen. Nat. Immunol. 2002; 3: 756-763.

14. Negrini S., Fenoglio D., Balestra P. et al. Endocrine regulation of suppressor lymphocytes. Role of the glucocorticoidsinduced TNF-like receptor. Ann. N.-Y. Acad. Sci. 2006; 1069: 377-385.

15. Pukhalsky A.L., Shmarina G.V., Alioshkin V.A., Sabelnikov A. HPA axis exhaustion and regulatory T cell accumulation in patients with a functional somatic syndrome: recent view on the problem of Gulf War veterans. J. Neuroimmunol. 2008; 196: 133-138.

16. Weiner H.L. Induction and mechanism of action of transforming growth factor- $\beta$-secreting Th3 regulatory cells. Immunol. Rev. 2001; 182: 207-214.

\section{Информация об авторах}

Пухальский Александр Леонидович - д. м. н., проф., главный научный сотрудник МГНЦ РАМН; тел.: +7-499-612-81-24; e-mail: osugariver@ yahoo.com

Шмарина Галина Васильевна - к. м. н., ведущий научный сотрудник МГНЦ РАМН; тел.: +7-499-612-81-24; e-mail: sakmarariver@yahoo.com Каширская Наталия Юрьевна - д. М. Н., проф., главный научный сотрудник МГНЦ РАМН; тел.: +7-495-254-90-49; e-mail: stanisl.vi@mtu-net.ru Передерко Людмила Васильевна - к. м. н., ординатор Российской детской клинической больницы Росздрава; тел.: +7-495-936-93-33; e-mail: russia-cf@mtu-net.ru

Капранов Николай Иванович - д. м. н., проф., руководитель научно-клинического отдела муковисцидоза МГНЦ РАМН; тел.: +7-495-254-90-49; e-mail: russia-cf@mtu-net.ru 